\title{
Microbial Induction of B and T Cell Areas in Rabbit Appendix
}

\author{
Nicholas B. Hanson and Dennis K. Lanning* \\ Department of Microbiology \& Immunology, Loyola University Chicago, 2160 S. 1st Ave. Maywood, \\ IL USA 60153
}

\begin{abstract}
Gut-associated lymphoid tissue (GALT) development requires interaction with the intestinal microbiota. Because murine secondary lymphoid tissue development is driven by positive feedback interactions between B cells and stromal cells, we used in situ hybridization to determine whether intestinal commensals influence such interactions during rabbit appendix development. The features of positive feedback interactions we examined (CXCL13 mRNA expression, B cell accumulation and FDC differentiation) increased during early follicle development, but stalled in the absence of intestinal commensals. These features were reinitiated by commensals that stimulated follicle development and intrafollicular B cell proliferation. Our results suggest that rabbit appendix follicles develop in two phases: an initial phase of B cell recruitment to nascent follicles, possibly through positive feedback interactions, and a subsequent phase of intrafollicular B cell proliferation stimulated by intestinal commensals. In addition, we found that intestinal commensals stimulate appendix CCL21 mRNA expression and $\mathrm{T}$ cell area formation.
\end{abstract}

\section{Keywords}

Chemokines; B cell follicles; B cell proliferation; Gut-associated lymphoid tissue (GALT); Intestinal commensals; Intestinal microbiota; Rabbit appendix; $\mathrm{T}$ cell areas

\section{Introduction}

The strategy rabbits use to generate a large B cell population expressing diverse antibody specificities differs significantly from that used by mice and humans. While B-lymphopoiesis continues throughout life in mice and humans, most B-lymphopoiesis in rabbits occurs early in ontogeny, decreasing by over $99 \%$ within a few months after birth [1]. Adult rabbit B cells are therefore presumably long-lived and/or self-renewing. In further contrast, rabbit B cells utilize a restricted number of different V, D and $\mathrm{J}$ gene segments during VDJ gene rearrangement, thereby generating a limited neonatal antibody repertoire. After leaving the bone marrow, newly developed B cells seed gut-associated lymphoid tissues (GALT), particularly the appendix and sacculus rotundus, where they proliferate and concomitantly diversify their $\mathrm{V}(\mathrm{D}) \mathrm{J}$ genes through gene conversion [2,3] and somatic hyper-point mutation $[4,5]$. These developmental events greatly expand the B cell population and extensively

\footnotetext{
*Corresponding Author: Dr. Dennis K. Lanning, Loyola University Chicago, Department of Microbiology \& Immunology, Building 105, Room 3845, 2160 South 1st Ave, Maywood, IL USA 60153, Phone: (708) 216-3389; Fax: (708) 216-9574, Email: dlannin@lumc.edu.

Publisher's Disclaimer: This is a PDF file of an unedited manuscript that has been accepted for publication. As a service to our customers we are providing this early version of the manuscript. The manuscript will undergo copyediting, typesetting, and review of the resulting proof before it is published in its final citable form. Please note that during the production process errors may be discovered which could affect the content, and all legal disclaimers that apply to the journal pertain.
} 
diversify the primary antibody repertoire to provide immune protection against foreign antigens.

The intestinal microbiota plays a crucial role in these developmental processes in rabbit GALT. This was first appreciated when Perey and Good [6] demonstrated that preventing microbial colonization of the appendix, through cecal ligation at birth, arrested appendix follicle development. Subsequently, rabbits raised under germ-free conditions were found to have markedly underdeveloped GALT and poor antibody responses to antigenic challenges $[7,8]$. Recent studies have shown that rabbit appendix development and VDJ gene diversification are induced by select members of the intestinal microbiota $[9,10]$. In one study, the intestinal microbiota was experimentally altered by hand raising sterilely derived rabbit pups under nongerm-free conditions, but without contact with normal rabbits and their microbiota [9]. GALT was underdeveloped and 70\% of the IgM VDJ genes from peripheral blood B cells were undiversified in these rabbits, suggesting that GALT development and VDJ gene diversification were not dependent simply on the presence, but on select members, of the intestinal microbiota. This was confirmed by experiments in which individual intestinal isolates were introduced into rabbit appendices rendered germ-free by microsurgical ligation at birth [10]. Although most of the bacterial isolates tested did not induce appendix follicle development or VDJ gene diversification, the combination of Bacteroides fragilis and Bacillus subtilis consistently induced both of these processes. These studies demonstrate that select intestinal commensals play an essential role in rabbit appendix development and primary antibody repertoire diversification.

The mechanism by which intestinal bacteria induce rabbit appendix development is not known. The formation of $\mathrm{B}$ and $\mathrm{T}$ cell areas in murine secondary lymphoid tissues is directed by regional expression of the chemokines CXCL13 and CCL19/CCL21, respectively [11,12]. Furthermore, B cell follicle development in murine secondary lymphoid tissues is driven by chemokine-mediated positive feedback interactions between B cells and stromal cells [13, 14]. Stromal cell expression of the B cell chemoattractant CXCL13 primes these interactions by attracting an initial cluster of $\mathrm{B}$ cells expressing the CXCL13 receptor, CXCR5, to the nascent follicle [12,14-16]. B cells are a major source of membrane lymphotoxin $\left(\mathrm{LT} \alpha_{1} \beta_{2}\right)$ and tumor necrosis factor (TNF), cytokines that promote follicular dendritic cell (FDC) development through engagement of their receptors, the lymphotoxin $\beta$ receptor (LT $\beta R$ ) and TNF receptor 1 (TNFR1), respectively [17-23]. In addition, $\mathrm{LT} \alpha_{1} \beta_{2}$ upregulates CXCL13 expression in stromal cells and FDCs, which attracts additional B cells to the developing follicle [14]. A positive feedback loop is thereby established that drives follicle development by promoting B cell recruitment and the formation of FDC networks. Positive feedback interactions appear to be of central importance in the development of the spleen, lymph nodes, and Peyer's patches in mice [13]. The development of $\mathrm{T}$ cell areas, although less clearly understood, is dependent on stromal expression of the chemokines CCL19 and CCL21, which attract CCR $7^{+} \mathrm{T}$ cells and dendritic cells $[11,24]$.

To gain insight into the mechanism by which intestinal commensals induce rabbit appendix development, we examined B and T cell area formation in normal and manipulated appendix. Our results suggest that appendix follicles develop in two phases: an initial phase, possibly driven by positive feedback interactions, during which $\mathrm{B}$ cells are recruited to the nascent follicle, and a subsequent phase driven by intrafollicular B cell proliferation stimulated by intestinal commensals. We also found that intestinal commensals stimulate, with varying effectiveness among species, appendix CCL21 mRNA expression and T cell area development. 


\section{Materials and Methods}

\section{$2.1 \mathrm{Imm} u n o f l u o r e s c e n c e$ analysis of thin tissue sections}

Tissues were harvested and frozen in TBS embedding medium (Triangle Biomedical Sciences, Durham, NC) in 2-methylbutane cooled in liquid nitrogen. Tissue sections $(7 \mu \mathrm{m})$ were cut with a cryostat microtome, fixed in cold acetone, and blocked with goat serum. Sections were stained with the following rabbit-specific or cross-reactive primary antibodies: biotinylated 367, a mouse anti-rabbit $\mathrm{C} \mu \mathrm{mAb}$ (BD Biosciences, Palo Alto, CA) [25]; mouse anti-rabbit CD4 mAb (KEN-4; BD Biosciences); mouse anti-rabbit CD8 mAb (12C7; Serotec Inc., Raleigh, NC); Ki-67 mAb for identification of proliferating cells (Pharmingen, San Diego, CA) [26]. PE-conjugated streptavidin (Invitrogen, Carlsbad, CA) and Cy2-conjugated goat antimouse F(ab) (BD Biosciences) were used as secondary reagents. Appropriate isotype-matched antibodies were used as negative controls. LigApx rabbit tissues were generously provided by Dr. Katherine L. Knight (Department of Microbiology and Immunology, Loyola University Chicago).

\subsection{Riboprobe preparation}

A 500-700 bp PCR product from each gene of interest was cloned into the pGEM-T vector (Promega, Madison, WI). Sense and anti-sense in vitro transcription templates were generated by PCR amplification from each plasmid, using the appropriate gene-specific forward or reverse primer with a plasmid-specific primer containing either the T7 or SP6 RNA polymerase promoter (respectively, T7 Univ: 5'-agtgaattgtaatacgactcactataggg-3' and SP6 Univ: 5'cgccaagctatttaggtgacactatagaatac-3'). PCR products were purified with Montage PCR centrifugal filters (Millipore Corp, Bedford, MA) and $200 \mathrm{ng}$ purified PCR product was used as template in in vitro transcription reactions containing RNA labeling mix with digoxigeninUTP (or with fluorescein-UTP for 2 color in situ hybridization) (Roche, Mannheim, Germany) and T7 or SP6 RNA polymerase (Fisher Scientific, Pittsburgh, PA). Plasmid template was digested with RNase-free DNase I (Fermentas Inc., Hanover, MD) and the reactions were stopped by addition of $0.2 \mathrm{M}$ EDTA. RNA transcript integrity and concentration was assessed by electrophoresis on denaturing 5\% polyacrylamide gels. GenBank accession numbers for nucleotide sequences used to prepare riboprobes: CXCL13 (EU407474), C $\mu$ (J00666; nucleotides 473-1041), CR1 (EU407475), CXCR5 (EU407476), LT $\beta$ (EU407477), LT $\alpha$ (M60340; nucleotides 1168-1243; 1327-1433; 1631-2041), CD3 (NM 001082001; nucleotides 50-588), and CCL21 (EU407478).

\subsection{In situ hybridization}

Tissue sections (10-12 $\mu \mathrm{m})$ were fixed in $4 \%$ paraformaldehyde and washed in ice-cold PBS. Sections were pre-equilibrated in $0.2 \mathrm{~N} \mathrm{HCl}$, permeabilized with pepsin (in $0.2 \mathrm{~N} \mathrm{HCl}$ ) (Roche, Mannheim, Germany) and washed in ice-cold PBS. Sections were pre-equilibrated in $0.1 \mathrm{M}$ triethanolamine and acetylated in $0.25 \%$ acetic anhydride (Sigma, St. Louis, MO) in $0.1 \mathrm{M}$ triethanolamine. Sections were washed in PBS, equilibrated in 5X SSC, and prehybridized (mRNA in situ hybridization solution, DAKO Corp., Carpinteria, CA), $70^{\circ} \mathrm{C}, 2 \mathrm{hr}$. Sections were hybridized with $10-30 \mathrm{ng} / \mathrm{ml}$ digoxigenin-labeled riboprobe, $70^{\circ} \mathrm{C}, 20 \mathrm{hr}$, in a humidified container (anti-sense riboprobes were used to detect specific mRNAs; sense riboprobes served as negative controls). Hybridized sections were stringently washed, blocked with $10 \%$ normal rabbit serum and incubated with HRP-conjugated anti-digoxigenin $\mathrm{F}\left(\mathrm{ab}^{\prime}\right)$ (DAKO). Sections were washed in TBST, incubated in biotinyl tyramide (DAKO Genpoint), washed in TBST, blocked (as above), and incubated with AP-conjugated anti-biotin F(ab') (DAKO). Sections were washed in TBST, developed with BCIP/NBT (Vector Labs, Burlingame, CA), mounted with Supermount aqueous mounting medium (BioGenex, San Ramon, CA) and cover slipped with Permount mounting medium (Fisher Scientific, Fair Lawn, NJ). Sections were 
photographed with a Leica DM IRB microscope (Leica Microsystems, Brannockburn, IL) using a MagnaFire 2.1C digital camera system (Optronics, Goleta, CA).

Two-color in situ hybridization was performed as above, except tissue sections were hybridized with both digoxigenin- and fluorescein-labeled riboprobes. The fluorescein-labeled riboprobe was detected with HRP-conjugated anti-FITC F(ab') (DAKO) and Cy3-tyramide (PerkinElmer Life Sciences, Boston, MA). HRP activity was exhausted by incubation in $3 \% \mathrm{H}_{2} \mathrm{O}_{2}$ for $1 \mathrm{hr}$. The digoxigenin-labeled riboprobe was detected with HRP-conjugated anti-digoxigenin $\mathrm{F}\left(\mathrm{ab}^{\prime}\right)$, followed by biotinyl tyramide amplification, AP-conjugated anti-biotin $\mathrm{F}\left(\mathrm{ab}^{\prime}\right)$ and ELF 97 substrate (Molecular Probes, Eugene, OR) or AlexaFluor 488-conjugated anti-biotin IgG1 (Molecular Probes). Sections were photographed with a Zeiss AxioSkop FISH microscope using MacProbe 4.1 software.

\subsection{LT $\beta R$-Ig and TNFR1-Ig Adenovirus Production}

The extracellular regions of LT $\beta R$ and TNFR1 were cloned from rabbit appendix cDNA (LT $\beta R$ PCR primers: RbLTBR KpnI f: 5'-ggtaccagtggccaccatgcgcccg-3', RbLTBR BamHI r: 5'-ggatcccagcacggtccetggcaacgg-3'; TNFR1 PCR primers: RbTNFR1 KpnI f: 5'ggtaccagcccaaatgggggagtgagag-3', RbTNFR1 BamHI r: 5'-ggatcccagcactgtggcgcctga- $3^{\prime}$ ). PCR products were cloned into the pGEM-T vector (Promega, Madison, WI) and the fidelity of the nucleotide sequences was determined using an automated ABI Prism 310 sequencer with Big Dye-labeled terminators (Perkin-Elmer Applied Biosystems, Foster City, CA). The cloned DNA was excised with KpnI and BamHI restriction endonucleases, gel-purified and ligated into the pCDNA 3.1 vector, similarly restriction digested, into which cDNA encoding the Fc region of rabbit IgG was previously cloned (kindly provided by Dr. D. A. Dichek, Univ. of Washington School of Medicine, Seattle, WA). The nucleotide sequences were determined, as above, to ensure in-frame fusion of the LT $\beta$ R and TNFR1 nucleotide sequences with that encoding the rabbit IgG Fc region. The fusion constructs were then cloned into the pShuttleCMV AdEasy transfer vector (Qbiogene, Carlsbad, CA), and viral stocks were prepared following the manufacturer's instructions. Briefly, the cloned constructs were linearized with PmeI and transformed into BJ5183-Ad competent cells (Strategene, La Jolla, CA). Recombinants were selected on kanamycin plates, amplified and transformed into DH10B competent cells. DNA from transformants was linearized with PacI and transfected into QBI-293A cells (Qbiogene). Virus was extracted from viral plaques by freeze thawing and lysates were used to infect QBI-293A cells for primary propagation and large-scale amplification. Viral bands were isolated on cesium chloride gradients, dialyzed, titered using the Tissue Culture Infectious Dose 50 (TCID50) method (Qbiogene) and stored at $-80^{\circ} \mathrm{C}$.

\subsection{Administration of recombinant adenovirus}

In $0.5 \mathrm{ml}$ PBS, $10^{9}$ LT $\beta R$-Ig and/or TNFR1-Ig recombinant viral particles were injected intraperitoneally into newborn rabbit pups and the rabbits were sacrificed 1 week or 3 weeks later for tissue collection. In one experiment, rabbits were reinfected at weekly intervals to ensure that the fusion protein titers remained high throughout a 3-week period. All animal studies were reviewed and approved by the Institutional Animal Care and Use Committee (IACUC) at Loyola University Chicago.

\subsection{Western Blot Analysis}

Ig fusion proteins were immunoprecipitated from sera with protein $\mathrm{G}$ beads. Samples were electrophoresed on a $10 \%$ resolving SDS-PAGE gel and transferred to a nitrocellulose membrane. Proteins were detected with a mouse anti-rabbit IgG mAb (C101-359; BD Biosciences), followed by HRP-conjugated donkey anti-mouse IgG (Jackson ImmunoResearch Labs, West Grove, PA) and ECL detection reagent (Amersham Biosciences, Piscataway, NJ), according to the manufacturer's instructions. Serum concentrations were 
determined by comparison of bands to those of standards of known concentration using ImageQuant TL v2005 software (Amersham Biosciences).

\section{Results}

\subsection{B cell follicle formation during early rabbit appendix development}

Rabbit appendix is composed of numerous large $\mathrm{B}$ cell follicles and interfollicular $\mathrm{T}$ cell areas, which are sites of CXCL13 and CCL21 mRNA expression, respectively (Fig. 1, A and B). We examined B cell follicle formation during neonatal rabbit appendix development by using in situ hybridization to search for evidence of positive feedback interactions between B cells and stromal cells/FDCs. Of the genes examined (CXCL13, C $\mu$, CR1 and LT $\beta$ ), only CXCL13 mRNA was expressed at birth, and this expression was confined to the appendix domes (Fig. $1 \mathrm{E}$, and data not shown). We first detected B-lymphocytes entering the appendix domes on postnatal day 2, with increasing numbers accumulating over subsequent days (Fig. 2, top row). We also found that CXCL13 mRNA expression expanded concomitantly with the influx of Blymphocytes, and remained confined to the developing follicles (Fig. 2, middle row).

We used a complement receptor 1 (CR1, or CD35) riboprobe to detect follicular dendritic cells (FDCs), because FDCs express high levels of CD35 [27]. The CR1 riboprobe detected cells that first appeared within developing follicles on postnatal day 3 (Fig. 2, bottom row), consistent temporally with positive feedback-driven FDC differentiation. We confirmed that our CR1 riboprobe did not detect B-lymphocytes, which express CR1 at low levels, by twocolor in situ hybridization of 5-day-old rabbit appendix with $\mathrm{C} \mu$ and $\mathrm{CR} 1$ riboprobes. We found that the $\mathrm{C} \mu$ and $\mathrm{CR} 1$ riboprobes detected distinct, closely apposed, cell populations, characteristic in appearance to that of B-lymphocyte:FDC clusters (Figure 3). Furthermore, unlike cells detected with the $\mathrm{C} \mu$ riboprobe, cells detected with the CR1 riboprobe were only seen within domes, suggesting they developed in situ, as expected for FDC differentiation.

By 1 week of age, well-developed appendix follicles contained numerous B cells, robust CXCL13 mRNA expression and well defined FDC clusters, as well as cells (presumably B cells) expressing CXCR5, LT $\beta$ and LT $\alpha$ mRNA, molecules critical for B-lymphocyte participation in positive feedback interactions (Figure 4 and data not shown). We conclude that the temporal pattern of initial stromal CXCL13 expression, subsequent B cell accumulation associated with increasing CXCL13 expression, and concurrent appearance of FDCs that we observed during postnatal appendix development is identical to that observed during positive feedback-mediated follicle development, in which B cells, attracted by stromal CXCL13 expression, stimulate increased stromal CXCL13 expression and FDC differentiation through signals mediated by membrane-associated $\mathrm{LT} \alpha_{1} \beta_{2}$ and TNF.

\subsection{Follicle development in the absence of intestinal microbiota}

To determine the role of intestinal commensals during appendix follicle development, we assessed CXCL13 expression, B cell recruitment and FDC differentiation (as identified by in situ hybridization with a CR1 riboprobe) in appendix rendered germ-free by ligation at birth to prevent bacterial colonization, while the vasculature was undisturbed (LigApx rabbits) [10] (samples generously provided by Dr. Katherine L. Knight). In germ-free appendix, follicles do not develop beyond the accumulation of small B cell clusters in the domes (Figure 5A, top left). We found, however, considerable CXCL13 mRNA expression and FDC differentiation in the appendix domes of LigApx rabbits (Figure 5A, top right and bottom left, respectively). The extent of FDC differentiation appeared comparable to that observed in normal appendix of 1-week-old rabbits (compare Figure 5A, bottom left, with Figure 4, top left). These results suggest that positive feedback interactions were initiated in germ-free 
appendix. If so, these interactions apparently stall in the absence of intestinal commensals, because follicles fail to develop beyond a rudimentary stage in germ-free appendix.

\subsection{Stimulation of follicle development by intestinal commensals}

To understand how intestinal bacteria stimulate follicle expansion, we examined CXCL13 mRNA expression, B cell clusters and FDC differentiation in follicles induced by intestinal commensals in LigApx rabbit appendix. Rhee et al. (2004) demonstrated that co-introducing Bacteroides fragilis and Bacillus subtilis isolates into LigApx rabbit appendix induced robust follicle expansion [10]. Together, these commensals induced intrafollicular B cell proliferation (Fig. 5B, bottom right), which did not occur in the absence of intestinal commensals (Figure $5 \mathrm{~A}$, bottom right). We found that follicle expansion induced by $B$. fragilis plus $B$. subtilis was accompanied by an increase in the size of B cell and FDC clusters, as well as increased CXCL13 mRNA expression (Figure 5B, top left, bottom left and data not shown), demonstrating that these features of positive feedback interactions, in addition to intrafollicular B cell proliferation, were stimulated by signals derived from B. fragilis plus B. subtilis.

\subsection{Impact of LT $\beta R$ and TNFR1 signaling blockade on rabbit appendix development}

During positive feedback-mediated follicle development in murine secondary lymphoid tissues, B cells deliver critical signals, via surface LT $\alpha_{1} \beta_{2}$ and TNF, through the lymphotoxin $\beta$ receptor (LT $\beta \mathrm{R})$ and TNF receptor 1 (TNFR1), respectively, expressed by stromal cells and FDCs [19-22]. To determine whether positive feedback interactions drive appendix follicle development, we blocked these signals with soluble LT $\beta$ R-Ig and/or TNFR1-Ig fusion proteins introduced into newborn rabbits via recombinant adenovirus. Littermate controls were infected with adenovirus expressing only the Ig portion of the fusion proteins, or with no adenovirus. The rabbits were sacrificed 1 or 3 weeks later for tissue analysis. We confirmed the presence of fusion proteins in peripheral blood by western blot analysis of sera (Figure 6A). We first assessed the impact of the Ig fusion proteins on spleen development, which in mice is highly dependent on both LT $\beta$ R and TNFR1 signaling [28]. Both the LT $\beta$ R-Ig (Figure 6B, first and second rows, right) and TNFR1-Ig (data not shown) fusion proteins markedly disrupted splenic $\mathrm{T}$ and $\mathrm{B}$ cell area formation at 1 and 3 weeks of age. Furthermore, each of the fusion proteins strikingly reduced both CXCL13 and CCL21 mRNA expression in the spleen at 3 weeks of age (LT $\beta$ R-Ig results shown in Figure 6B, third and fourth rows, right). These results demonstrate that, as in the mouse, both LT $\beta$ R and TNFR1 signaling are required for B and T cell area formation in the rabbit spleen.

The LT $\beta$ R-Ig fusion protein, alone or with the TNFR1-Ig fusion protein, hindered follicle formation during the first week of appendix development (Figure 6C, top right). By visual inspection, the follicles were markedly smaller than those of control littermates and contained reduced numbers of $\mathrm{B}$ cells, demonstrating an important role for LT $\beta \mathrm{R}$ signaling during early follicle development. Surprisingly, however, appendix follicles were normally developed by 3 weeks of age, even when both fusion proteins were introduced weekly (Fig. 6C, bottom right). These results suggest that, in marked contrast to the spleen, neither LT $\beta$ R nor TNFR1 signaling is critical for appendix development after the first week of life and that some mechanism other than positive feedback interaction drives follicle development at this time. We cannot, however, rule out the possibility that the spleen is much more sensitive to disruption of LT $\beta R$ and TNFR1 signaling and that serum levels of the fusion proteins were insufficient to impede appendix development after the first week of life. Taken together, our results suggest that rabbit appendix follicles develop in two phases. During an initial phase, comprising approximately the first week of life, peripheral B cells are recruited to nascent follicles, possibly through positive feedback interactions and without a requirement for intestinal commensals. In the second phase, follicle expansion is driven by intrafollicular B cell proliferation stimulated by intestinal commensals. 


\subsection{T cell area formation during early rabbit appendix development}

Large $\mathrm{T}$ cell areas are located in the interfollicular regions of the rabbit appendix. To study $\mathrm{T}$ cell area development, we examined CCL21 expression and T cell localization, by in situ hybridization, during early appendix development. We found that CCL21 mRNA was first expressed approximately 2-3 days after birth, in the basolateral region of the appendix, well below B cell clusters forming in appendix domes (Figure 7B and data not shown; some CCL21 mRNA expression was detectable by day 2 with the more sensitive BCIP staining). CCL21 mRNA expression increased and expanded rapidly over subsequent days, first contacting, and then surrounding, the growing B cell follicles (Figure 7C and D). As shown in Figure 7E, immigrating $\mathrm{T}$ cells localized to the region of CCL21 expression. The characteristic interfollicular localization of $\mathrm{T}$ cell areas, therefore, results from $\mathrm{B}$ cell follicles expanding through a previously uninterrupted region of CCL21 mRNA expression.

\subsection{Impact of intestinal microbiota on appendix $T$ cell area formation}

We examined CCL21 expression and T cell distribution in LigApx rabbit tissues to determine whether $\mathrm{T}$ cell area formation is influenced by the intestinal microbiota. In the absence of intestinal microbiota, CCL21 mRNA expression was almost completely confined to small regions at the basolateral margin of the B cell clusters (Figure 8A and G). Some CCL21 mRNA expression was also seen beneath the follicle-associated epithelium (FAE), as well as occasionally spanning the regions between adjacent B cell clusters, suggesting the initiation of T cell area formation. Few T cells, however, accumulated in these regions of CCL21 mRNA expression (Figure $8 \mathrm{M}$ ). These features were not significantly altered by the introduction of an $E$. coli isolate into germ-free appendix (Figure $8 \mathrm{~B}, \mathrm{H}$ and $\mathrm{N}$ ). The introduction of Clostridium subterminale (Figure 8C, I and O) or Enterobacter faecalis (Figure 8D, J and P) isolates into germ-free appendix, however, induced nearly continuous lateral CCL21 mRNA expression, as well as interfollicular regions of $\mathrm{T}$ cell accumulation. More robust continuous lateral CCL21 mRNA expression, as well as well defined interfollicular T cell area formation, was induced by introduction of a Bacteroides fragilis isolate (Figure 8E, K and Q). These features were most pronounced following co-introduction of Bacteroides fragilis and Bacillus subtilis isolates, where the lateral continuity of CCL21 mRNA expression was interrupted by robust follicle expansion (Figure $8 \mathrm{~F}, \mathrm{~L}$ and $\mathrm{R}$ ). These results demonstrate that signals derived from members of the intestinal microbiota induce appendix CCL21 mRNA expression and T cell area formation, and that commensals differ in their ability to induce these developmental processes.

\section{Discussion}

In the rabbit, the appendix functions as an important site for expansion of the B cell population and diversification of the primary antibody repertoire [3,25]. Early in postnatal life, newly developed B cells emigrate from the bone marrow and migrate to GALT, of which the appendix is a major site [29,30]. Within GALT, B cells proliferate extensively and diversify their V(D) $\mathrm{J}$ genes through somatic gene conversion and somatic hyper-point mutation [2-5]. These developmental processes are driven by select members of the intestinal microbiota $[9,10]$. B cell proliferation and $\mathrm{V}(\mathrm{D}) \mathrm{J}$ gene diversification, for example, do not occur in appendices rendered germ-free through surgical manipulation, and are stimulated by subsequent inoculation with only a few of the bacterial isolates that have been tested $[9,10]$. The mechanisms by which intestinal commensals stimulate these developmental processes are not currently understood. In the present study, we sought to gain insight into these mechanisms by examining the impact of intestinal commensals on positive feedback interactions between $\mathrm{B}$ cells and stromal cells, as well as on $\mathrm{T}$ cell area formation, in the rabbit appendix. 
In mice, follicle development in secondary lymphoid tissues is driven by chemokine-mediated positive feedback interactions between B cells and stromal cells [13,14]. Stromal cells initiate these interactions by expressing the B cell chemoattractant CXCL13, which attracts an initial cluster of B cells to the nascent follicle [14]. B cells in turn upregulate stromal cell CXCL13 expression, and stimulate FDC differentiation, through membrane-expressed lymphotoxin $\alpha_{1} \beta_{2}\left(\mathrm{LT} \alpha_{1} \beta_{2}\right)$ and tumor necrosis factor (TNF). The resultant positive feedback loop drives follicle development by promoting B cell recruitment and the formation of FDC networks. We reasoned that similar feedback loop interactions likely also contribute to follicle development in rabbit appendix and, if so, intestinal commensals must somehow influence these interactions. To test this hypothesis, we used in situ hybridization and immunohistochemistry to search for evidence of positive feedback interactions during follicle development in normal and manipulated appendices.

Our results suggest that positive feedback interactions drive early follicle development. We found, for example, that stromal cells in appendix domes express CXCL13 at birth, before the arrival of the first B cells. This early CXCL13 expression is reminiscent of murine stromal cells priming positive feedback interactions in nascent follicles by expressing a basal level of CXCL13 to attract an initial cluster of B cells [14]. Consistent with this interpretation, we found that $\mathrm{B}$ cells began immigrating into the domes on postnatal day 2. Over postnatal days 3 through 5, additional B cell immigration coincided with increasing CXCL13 expression within the appendix domes and, by postnatal day 3, the appearance of FDC clusters. The temporal progression of these events is consistent with that observed during positive feedback loopdriven follicle development. In addition, developing follicles contained cells (presumably B cells) expressing CXCR5, LT $\alpha$ and LT $\beta$ mRNA, molecules critical for positive feedback interactions. Finally, LT $\beta$ R-Ig and TNFR1-Ig fusion proteins markedly hindered early follicle development.

We unexpectedly found evidence that these initial events (increased stromal cell CXCL13 mRNA expression, B cell recruitment and FDC differentiation) also occurred in germ-free appendices. In these appendices, however, follicles did not develop beyond an early, rudimentary stage. Taken together, these results suggest that follicle development is initiated by positive feedback interactions, without a requirement for signals derived from intestinal commensals. These results further suggest that this initial development is the first of two phases of follicle development, the second phase requiring microbial signals and thus not occurring in germ-free appendices. We suggest that the first phase of follicle development occurs during approximately the first week of life, waning shortly thereafter due to declining numbers of immigrating B cells to sustain ongoing positive feedback interactions. This view is supported by a recent study suggesting that $B$ cells developmentally seed the rabbit appendix during the first week of life [31]. Sinha et al. (2006) reported evidence suggesting that B cell immigration into the neonatal rabbit appendix occurs during a short early time period delimited by the regulated expression of peripheral lymph node addressin (PNAd) on high endothelial venules (HEVs) [31]. These investigators demonstrated that PNAd ${ }^{+}$HEVs increase sharply in total area during the first week of rabbit appendix development and decline sharply in total area shortly thereafter. These authors also found, in adoptive transfer experiments, that 100 times more B cells were recruited into the appendices of 1-week-old, than 6-week-old, rabbits. We therefore suggest that follicle development stalled in germ-free appendices because a developmentally regulated decline in B cell immigration stalled positive feedback interactions, and the absence of microbial signals prevented commencement of the second phase of follicle development.

Although the microbial signals that initiate the second phase of follicle development are not known, they likely drive follicle expansion by stimulating extensive intrafollicular B cell proliferation. The presence of large numbers of proliferating $B$ cells in rabbit appendix follicles 
has long been noted [32]. Furthermore, Rhee et al. (2004) reported that follicle development induced in germ-free appendices after the introduction of bacterial isolates was accompanied by intrafollicular B cell proliferation [10]. It is tempting to speculate that B cells produced during intrafollicular proliferation, induced by microbial signals, drive positive feedback interactions within developing follicles after B cell immigration wanes. All of the parameters of positive feedback interactions we examined (CXCL13 expression, B cell accumulation and FDC differentiation), for example, increased during proliferative follicle expansion induced by introducing $B$. fragilis + B. subtilis into germ-free appendix. The results of our LT $\beta \mathrm{R}-\mathrm{Ig}$ and TNFR1-Ig fusion protein experiments, however, do not appear to support this idea.

We introduced soluble LT $\beta R$-Ig and TNFR1-Ig fusion proteins into newborn rabbits via an adenovirus system to test directly, by blocking LT $\beta$ R and TNFR1 signaling, whether positive feedback interactions drive appendix follicle development. We were surprised to find that, although both fusion proteins dramatically reduced CXCL13 and CCL21 mRNA expression and $\mathrm{B}$ and $\mathrm{T}$ cell area formation in the spleen, appendix follicles developed normally by 3 weeks of age. The LT $\beta$ R-Ig fusion protein did, however, significantly hinder appendix follicle development during the first week of life, suggesting, together with our in situ hybridization results, that positive feedback interactions play an important role during the first phase of follicle development. It is not clear why the fusion proteins had no impact on the second phase of appendix follicle development. It is possible that the spleen is much more sensitive to, or received higher local concentrations of, the fusion proteins and that serum levels of the fusion proteins were not sufficient to interrupt the proliferative phase of appendix follicle development. It is also possible that novel or redundant signals might drive positive feedback interactions during the second stage of follicle development. Alternatively, the proliferative phase of follicle development might be driven by some other mechanism. Although positive feedback interactions drive follicle development in murine secondary lymphoid tissues, for example, germinal centers develop independently of CXCL13 [14]. Similarly, despite lacking lymph nodes and Peyer's patches, LT $\alpha$-deficient mice occasionally develop rudimentary mesenteric lymph nodes [33]. Nasal-associated lymphoid tissues (NALT) also develop independently of LT $\alpha[34,35]$. Whatever mechanism drives proliferative expansion of follicles in rabbit appendix, it clearly requires signals derived from the intestinal microbiota, and intestinal commensals differ in their ability to deliver these signals.

The cellular and molecular mechanisms controlling $\mathrm{T}$ cell area formation in secondary lymphoid tissues are not as well understood as those controlling B cell follicle development. Splenic T cell area formation in the mouse is directed by regional stromal cell CCL19 and CCL21 expression that is dependent on both LT $\beta R$ and TNFR1 signaling [28]. Similarly, we found that both signals are required for CCL21 expression and T cell area formation in the rabbit spleen. As we observed with follicle development, however, normal T cell areas formed, by 3 weeks of age, when both signals were presumably blocked with Ig fusion proteins. In addition, we unexpectedly found that, also like follicle development, CCL21 mRNA expression and $\mathrm{T}$ cell area formation are stimulated by intestinal commensals and that commensals differ in their ability to induce or maintain these developmental events.

By examining early postnatal appendix development, we found that the characteristic interfollicular organization of $\mathrm{T}$ cell areas in adult appendix results from an interesting developmental process. Unlike CXCL13, CCL21 was not expressed in newborn appendix. Appendix T cell area formation was initiated by the onset of CCL21 expression, 2-3 days after birth, in the basolateral region of the appendix. The region of CCL21 mRNA expression, initially localized well below B cell clusters forming in the domes, expanded markedly over subsequent days, contacting and surrounding the growing follicles, which simultaneously distended downward through it. T cell areas ultimately occupy their characteristic interfollicular location following complete distension of the expanding follicles through the 
region of CCL21 expression. Furthermore, we found that this developmental process, like follicle formation, is influenced differentially by intestinal commensals. In sterile appendix, CCL21 mRNA expression was largely confined to the basolateral margins of domes, suggesting a possible role for B cells in its induction or maintenance. Nonetheless, few T cells localized to these regions. It is possible that these regions did not express CCL21 protein or that $\mathrm{T}$ cell expression of the CCL21 receptor, CCR7, requires signals from intestinal commensals. While appendix colonization with $E$. coli resulted in little, if any, additional CCL21 expression, both E. faecalis and $C$. subterminale induced nearly continuous CCL21 expression throughout the appendix, as well as localized regions of T cell accumulation. $B$. fragilis, especially in combination with $B$. subtilis, stimulated robust CCL21 expression and well-formed $\mathrm{T}$ cell areas. In the rabbit appendix, therefore, the development of $\mathrm{T}$ cell areas, like that of follicles, requires signals derived from the intestinal microbiota, and intestinal commensals differ in their ability to supply these signals.

Differential impact of intestinal commensals on T cell accumulation and CCL21 expression has been reported in mouse Peyer's patches [36]. Maeda et al. (2001) reported that some bacterial species, when mono-associated with germ-free mice, induced high levels of Peyer's patch CCL21 mRNA expression and T cell infiltration, while others did not [36]. In contrast to our results, these authors found that E. coli induced high levels of Peyer's patch CCL21 expression and T cell infiltration. Because E. coli induced little, if any, CCL21 expression and $\mathrm{T}$ cell accumulation in rabbit appendix, these results suggest that the response of GALT to different intestinal commensals might differ between species or anatomical sites. The mechanism by which the intestinal microbiota influences these features of GALT development is not known. This is a potentially important area of study, because CCL21, in addition to facilitating $\mathrm{T}$ cell-dendritic cell interactions through its chemoattractant properties, possesses potent stimulatory activities. CCL21, for example, costimulates naïve T cell proliferation and $\mathrm{T}_{\mathrm{H}} 1$ polarization, and induces proinflammatory DC differentiation [37,38]. Elucidating the mechanism by which intestinal commensals influence CCL21 expression and T cell area formation in GALT, therefore, might provide insight into the host-microbial relationships underlying, not only rabbit appendix development, but human health and disease.

Our results demonstrate that both $\mathrm{T}$ and $\mathrm{B}$ cell area formation in the rabbit appendix are dependent on signals delivered by intestinal commensals. Our results further suggest that $\mathrm{B}$ cell follicles develop in two phases: an initial phase driven by B cell recruitment, possibly through positive feedback interactions, and a second phase driven by intrafollicular B cell proliferation stimulated by intestinal commensals. While the nature of the commensal-derived signals driving these developmental processes is not known, experimental evidence suggests that $B$ cell proliferation within follicles is not initiated by antigen-specific adaptive immune responses, but by signals that stimulate B cells polyclonally [39-41]. Polyclonal B cell activation could occur through recognition of microbial molecules by pattern-recognition receptors such as Toll-like receptors [42] or through antigen-independent BCR stimulation by a superantigen expressed, or induced, by intestinal commensals [43]. B cells could also be polyclonally stimulated by cytokines or other stimulatory molecules expressed by dendritic cells activated by interaction with intestinal commensals. The dependence of both $\mathrm{T}$ and $\mathrm{B}$ cell area formation in the rabbit appendix on signals derived from intestinal commensals might indicate that the two processes are inter-dependent, perhaps facilitating cellular interactions necessary to induce proliferative B cell expansion and V(D)J gene diversification. Further exploration of the potential mechanisms by which select intestinal commensals induce B and $\mathrm{T}$ cell area formation in rabbit GALT will increase our understanding of the host-microbial interactions that drive these developmental processes. 


\section{Acknowledgements}

We thank Katherine L. Knight for generously providing LigApx rabbit appendix samples for these studies. This work was supported by NIH RO1 Grant 1 RO1 AI49458-01A1.

\section{Abbreviations \\ $\mathrm{C} \mu($ or $\mu)$ \\ IgM constant region}

CR1

complement receptor 1

FDC

follicular dendritic cell

HEV

high endothelial venule

$\operatorname{LigApx}$

ligated appendix

LT (or LT $\left.\alpha_{1} \boldsymbol{\beta}_{2}\right)$

lymphotoxin

LT $\mathbf{R R}$

lymphotoxin beta receptor

TNFR1

tumor necrosis factor receptor 1

PNAd

peripheral lymph node addressin

TNF

tumor necrosis factor

\section{References}

1. Jasper PJ, Zhai SK, Kalis SL, Kingzette M, Knight KL. B lymphocyte development in rabbit: progenitor B cells and waning of B lymphopoiesis. J Immunol 2003;171:6372-6380. [PubMed: 14662835]

2. Becker RS, Knight KL. Somatic diversification of immunoglobulin heavy chain VDJ genes: Evidence for somatic gene conversion in rabbits. Cell 1990;63:987-997. [PubMed: 2124176]

3. Weinstein PD, Anderson AO, Mage RG. Rabbit IgH sequences in appendix germinal centers: VH diversification by gene conversion-like and hypermutation mechanisms. Immunity 1994;1:647-659. [PubMed: 7600292]

4. Pospisil R, Young-Cooper GO, Mage RG. Preferential expansion and survival of B lymphocytes based on VH framework 1 and framework 3 expression: "Positive" selection in appendix of normal and VHmutant rabbits. Proc Natl Acad Sci USA 1995;92:6961-6965. [PubMed: 7624353]

5. Lanning DK, Knight KL. Somatic hypermutation: Mutations 3' of rabbit VDJ H-chain genes. J Immunol 1997;159:4403-4407. [PubMed: 9379038]

6. Perey DYE, Good RA. Experimental arrest and induction of lymphoid development in intestinal lymphoepithelial tissues of rabbits. Lab Invest 1968;18:15-25. [PubMed: 4966916]

7. Stepankova R, Kovaru F, Kruml J. Lymphatic tissue of the intestinal tract of germfree and conventional rabbits. Folia Microbiol 1980;25:491-495. [PubMed: 7439845]

8. Tlaskalova, H.; Sterzl, J.; Hajek, P.; Pospilil, M.; Riha, I.; Marvanova, H.; Kamarytova, V.; Mandel, L.; Kruml, J.; Kovaru, F. The development of antibody formation during embryonal and postnatal 
periods. In: Sterzl, JaRI., editor. Developmental aspects of antibody formation. Academia; Prague: 1970. p. 767-790.

9. Lanning D, Sethupathi P, Rhee KJ, Zhai SK, Knight KL. Intestinal microflora and diversification of the rabbit antibody repertoire. J Immunol 2000;165:2012-2019. [PubMed: 10925284]

10. Rhee KJ, Sethupathi P, Driks A, Lanning DK, Knight KL. Role of commensal bacteria in development of gut-associated lymphoid tissues and preimmune antibody repertoire. J Immunol 2004;172:11181124. [PubMed: 14707086]

11. Gunn MD, Tangemann K, Tam C, Cyster JG, Rosen SD, Williams LT. A chemokine expressed in lymphoid high endothelial venules promotes the adhesion and chemotaxis of naive T lymphocytes. Proc Natl Acad Sci U S A 1998;95:258-263. [PubMed: 9419363]

12. Legler DF, Loetscher M, Roos RS, Clark-Lewis I, Baggiolini M, Moser B. B cell-attracting chemokine 1, a human CXC chemokine expressed in lymphoid tissues, selectively attracts B lymphocytes via BLR1/CXCR5. J Exp Med 1998;187:655-660. [PubMed: 9463416]

13. Fu YX, Chaplin DD. Development and maturation of secondary lymphoid tissues. Ann Rev Immunol 1999;17:399-433. [PubMed: 10358764]

14. Ansel KM, Ngo VN, Hyman PL, Luther SA, Forster R, Sedgwick JD, Browning JL, Lipp M, Cyster JG. A chemokine-driven positive feedback loop organizes lymphoid follicles. Nature 2000;406:309314. [PubMed: 10917533]

15. Forster R, Mattis AE, Kremmer E, Wolf E, Brem G, Lipp M. A putative chemokine receptor, BLR1, directs $\mathrm{B}$ cell migration to defined lymphoid organs and specific anatomic compartments of the spleen. Cell 1996;87:1037-1047. [PubMed: 8978608]

16. Gunn MD, Ngo VN, Ansel KM, Ekland EH, Cyster JG, Williams LT. A B-cell-homing chemokine made in lymphoid follicles activates Burkitt's lymphoma receptor-1. Nature 1998;391:799-803. [PubMed: 9486651]

17. Fu YX, Huang G, Wang Y, Chaplin DD. B lymphocytes induce the formation of follicular dendritic cell clusters in a lymphotoxin alpha-dependent fashion. J Exp Med 1998;187:1009-1018. [PubMed: 9529317]

18. Gonzalez M, Mackay F, Browning JL, Kosco-Vilbois MH, Noelle RJ. The sequential role of lymphotoxin and B cells in the development of splenic follicles. J Exp Med 1998;187:997-1007. [PubMed: 9529316]

19. Endres R, Alimzhanov MB, Plitz T, Futterer A, Kosco-Vilbois MH, Nedospasov SA, Rajewsky K, Pfeffer K. Mature follicular dendritic cell networks depend on expression of lymphotoxin beta receptor by radioresistant stromal cells and of lymphotoxin beta and tumor necrosis factor by B cells. J Exp Med 1999;189:159-168. [PubMed: 9874572]

20. Rennert PD, Browning JL, Mebius R, Mackay F, Hochman PS. Surface lymphotoxin alpha/beta complex is required for the development of peripheral lymphoid organs. J Exp Med 1996;184:1999_ 2006. [PubMed: 8920886]

21. Futterer A, Mink K, Luz A, Kosco-Vilbois MH, Pfeffer K. The lymphotoxin beta receptor controls organogenesis and affinity maturation in peripheral lymphoid tissues. Immunity 1998;9:59-70. [PubMed: 9697836]

22. Neumann B, Luz A, Pfeffer K, Holzmann B. Defective Peyer's patch organogenesis in mice lacking the 55-kD receptor for tumor necrosis factor. J Exp Med 1996;184:259-264. [PubMed: 8691140]

23. Pasparakis M, Alexopoulou L, Grell M, Pfizenmaier K, Bluethmann H, Kollias G. Peyer's patch organogenesis is intact yet formation of B lymphocyte follicles is defective in peripheral lymphoid organs of mice deficient for tumor necrosis factor and its 55-kDa receptor. Proc Natl Acad Sci U S A 1997;94:6319-6323. [PubMed: 9177215]

24. Hedrick JA, Zlotnik A. Identification and characterization of a novel beta chemokine containing six conserved cysteines. J Immunol 1997;159:1589-1593. [PubMed: 9257816]

25. Vajdy M, Sethupathi P, Knight KL. Dependence of antibody somatic diversification on gut-associated lymphoid tissue in rabbits. J Immunol 1998;160:2725-2729. [PubMed: 9510172]

26. Falini B, Flenghi L, Fagioli M, Stein H, Schwarting R, Riccardi C, Manocchio I, Pileri S, Pelicci PG, Lanfrancone L. Evolutionary conservation in various mammalian species of the human proliferationassociated epitope recognized by the Ki-67 monoclonal antibody. J Histochem Cytochem 1989;37:1471-1478. [PubMed: 2476477] 
27. Reynes M, Aubert JP, Cohen JH, Audouin J, Tricottet V, Diebold J, Kazatchkine MD. Human follicular dendritic cells express CR1, CR2, and CR3 complement receptor antigens. J Immunol 1985;135:2687-2694. [PubMed: 2411809]

28. Ngo VN, Korner H, Gunn MD, Schmidt KN, Riminton DS, Cooper MD, Browning JL, Sedgwick JD, Cyster JG. Lymphotoxin- $\alpha / \beta$ and tumor necrosis factor are required for stromal cell expression of homing chemokines in B and T cell areas of the spleen. J Exp Med 1999;189:403-412. [PubMed: 9892622]

29. Knight KL, Crane MA. Generating the antibody repertoire in rabbit. Adv Immunol 1994;56:179218. [PubMed: 8073947]

30. Pospisil R, Mage RG. Rabbit appendix: a site of development and selection of the B cell repertoire. Curr Top Microbiol Immunol 1998;229:59-70. [PubMed: 9479848]

31. Sinha RK, Alexander C, Mage RG. Regulated expression of peripheral node addressin-positive high endothelial venules controls seeding of B lymphocytes into developing neonatal rabbit appendix. Vet Immunol Immunopathol 2006;110:97-108. [PubMed: 16249036]

32. Apte SS. Ki-67 monoclonal antibody (MAb) reacts with a proliferation associated nuclear antigen in the rabbit Oryctolagus cuniculus. Histochemistry 1990;94:201-204. [PubMed: 2358378]

33. Banks TA, Rouse BT, Kerley MK, Blair PJ, Godfrey VL, Kuklin NA, Bouley DM, Thomas J, Kanangat S, Mucenski ML. Lymphotoxin-alpha-deficient mice. Effects on secondary lymphoid organ development and humoral immune responsiveness. J Immunol 1995;155:1685-1693. [PubMed: 7636227]

34. Harmsen A, Kusser K, Hartson L, Tighe M, Sunshine MJ, Sedgwick JD, Choi Y, Littman DR, Randall TD. Cutting edge: organogenesis of nasal-associated lymphoid tissue (NALT) occurs independently of lymphotoxin-alpha (LT alpha) and retinoic acid receptor-related orphan receptor-gamma, but the organization of NALT is LT alpha dependent. J Immunol 2002;168:986-990. [PubMed: 11801629]

35. Fukuyama S, Hiroi T, Yokota Y, Rennert PD, Yanagita M, Kinoshita N, Terawaki S, Shikina T, Yamamoto M, Kurono Y, Kiyono H. Initiation of NALT organogenesis is independent of the IL-7R, LTbetaR, and NIK signaling pathways but requires the Id2 gene and CD3(-)CD4(+)CD45(+) cells. Immunity 2002;17:31-40. [PubMed: 12150889]

36. Maeda Y, Noda S, Tanaka K, Sawamura S, Aiba Y, Ishikawa H, Hasegawa H, Kawabe N, Miyasaka $\mathrm{M}$, Koga Y. The failure of oral tolerance induction is functionally coupled to the absence of $\mathrm{T}$ cells in Peyer's patches under germfree conditions. Immunobiology 2001;204:442-457. [PubMed: 11776399]

37. Flanagan K, Moroziewicz D, Kwak H, Horig H, Kaufman HL. The lymphoid chemokine CCL21 costimulates naive $\mathrm{T}$ cell expansion and Th1 polarization of non-regulatory CD4+ T cells. Cell Immunol 2004;231:75-84. [PubMed: 15919372]

38. Marsland BJ, Battig P, Bauer M, Ruedl C, Lassing U, Beerli RR, Dietmeier K, Ivanova L, Pfister T, Vogt L, Nakano H, Nembrini C, Saudan P, Kopf M, Bachmann MF. CCL19 and CCL21 induce a potent proinflammatory differentiation program in licensed dendritic cells. Immunity 2005;22:493505. [PubMed: 15845453]

39. Lanning DK, Rhee KJ, Knight KL. Intestinal bacteria and development of the B-lymphocyte repertoire. Trends Immunol 2005;26:419-425. [PubMed: 15967718]

40. Sehgal D, Obiakor H, Mage RG. Distinct clonal Ig diversification patterns in young appendix compared to antigen-specific splenic clones. J Immunol 2002;168:5424-5433. [PubMed: 12023335]

41. Rhee KJ, Jasper PJ, Sethupathi P, Shanmugam M, Lanning D, Knight KL. Positive selection of the peripheral B cell repertoire in gut-associated lymphoid tissues. J Exp Med 2005;201:55-62. [PubMed: 15623575]

42. Takeda K, Kaisho T, Akira S. Toll-like receptors. Annu Rev Immunol 2003;21:335-376. [PubMed: 12524386]

43. Casola S, Otipoby KL, Alimzhanov M, Humme S, Uyttersprot N, Kutok JL, Carroll MC, Rajewsky K. B cell receptor signal strength determines B cell fate. Nat Immunol 2004;5:317-327. [PubMed: 14758357]

44. Frohman MA. Rapid amplification of complementary DNA ends for generation of full-length complementary DNAs: Thermal RACE. Meth Enzymol 1993;218:340-356. [PubMed: 7685466] 

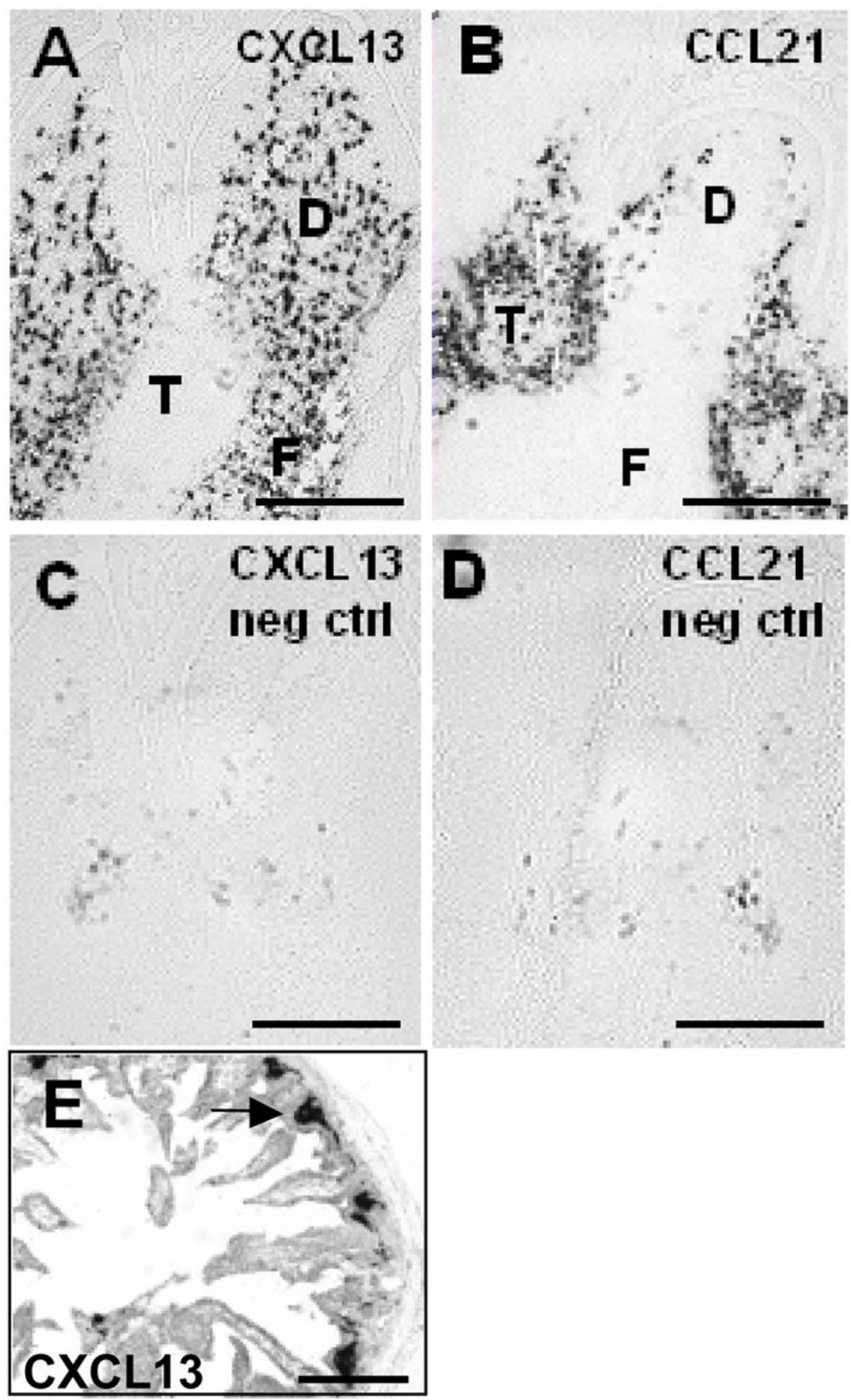

Figure 1.

CXCL13 and CCL21 mRNA in situ hybridization analysis of rabbit appendix sections. Six week appendix sections stained with: $A$, CXCL13 riboprobe; $B$, CCL21 riboprobe. $C$, CXCL13 negative control riboprobe; $D$, CCL21 negative control riboprobe. $E$, Newborn appendix section stained with CXCL13 riboprobe. CXCL13 mRNA expression within an appendix dome is indicated by an arrow. D, dome, F, follicle, T, T cell area. Magnification: 100X; Scale bars: $250 \mu \mathrm{m}$. 


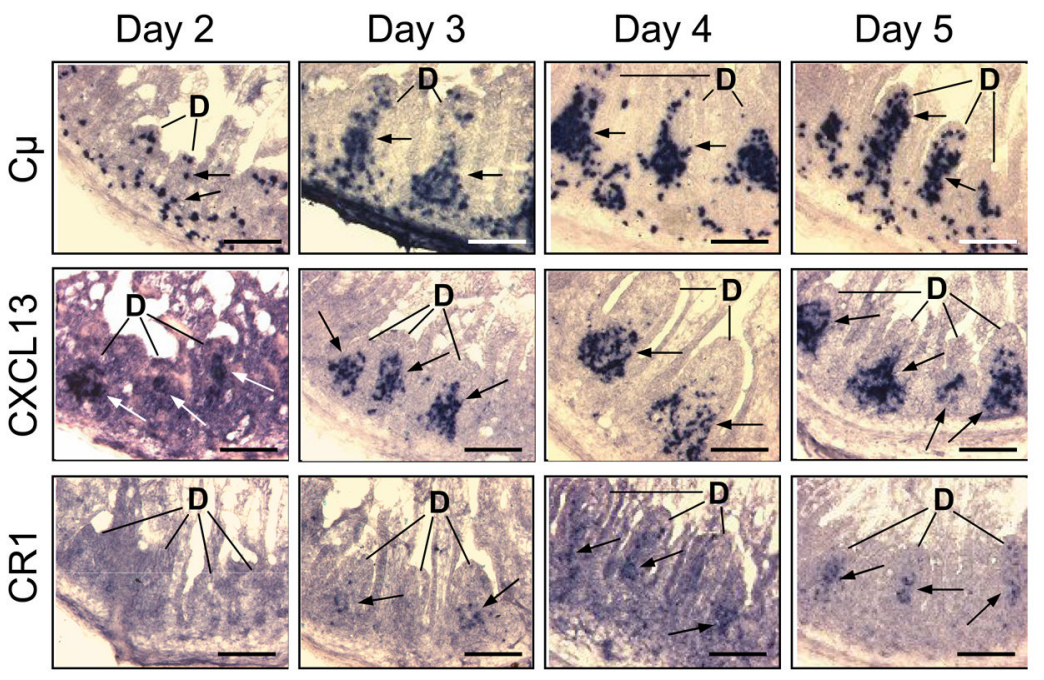

Figure 2.

Time course analysis of B cell immigration, CXCL13 mRNA expression and FDC cluster formation in postnatal rabbit appendix. In situ hybridization analysis with the following riboprobes: $\mathrm{C} \mu$, to detect B cells (arrows) (top row); CXCL13 (arrows) (middle row); complement receptor 1 (CR1), to detect FDC clusters (arrows) (bottom row). Rabbit age is indicated above each column. Appendix lumen located at upper right in all panels. D, dome. Magnification: 200X; Scale bars: $100 \mu \mathrm{m}$. 

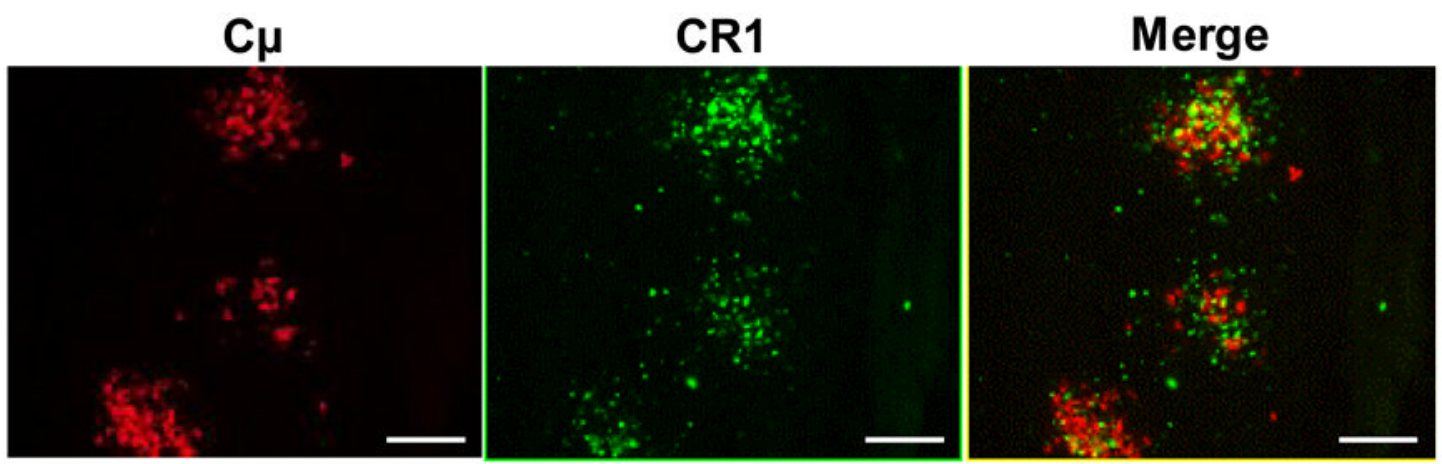

Figure 3.

Two-color RNA in situ hybridization analysis of B cell-FDC clusters from appendix of a 5day-old rabbit. B cells are stained with a $\mathrm{C} \mu$ riboprobe (red; left panel) and FDCs are stained with a CR1 riboprobe (green; middle panel). The merged hybridization results are shown in the right panel. Magnification: 200X; Scale bars: $100 \mu \mathrm{m}$. 


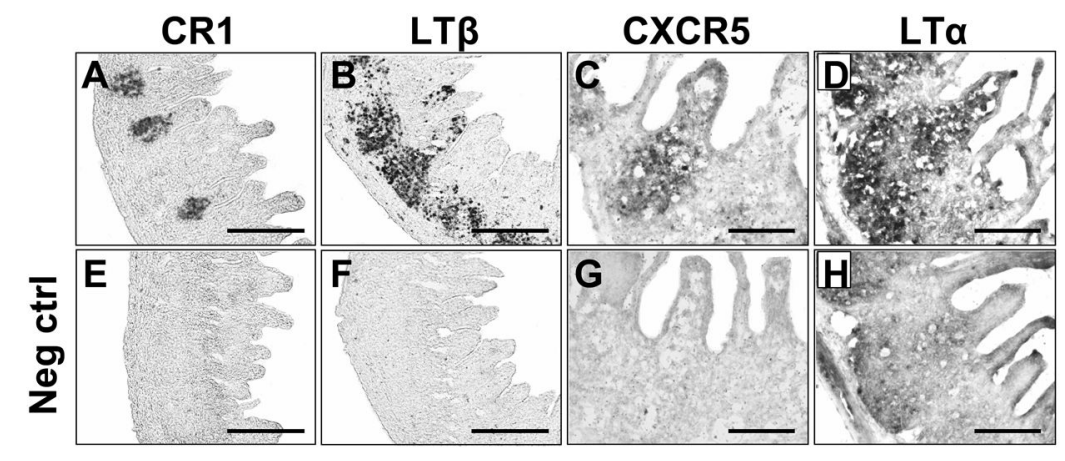

Figure 4.

RNA in situ hybridization analysis of appendix sections from 1-week-old rabbits. Riboprobes used for staining are indicated above each column. Lower panels: negative controls.

Magnification: CR1, LT $\beta$ : 100X; CXCR5, LT $\alpha$ : 200X; Scale bars: $250 \mu \mathrm{m}$ (100X), $100 \mu \mathrm{m}$ (200X). 


\section{A Germ-free appendix}
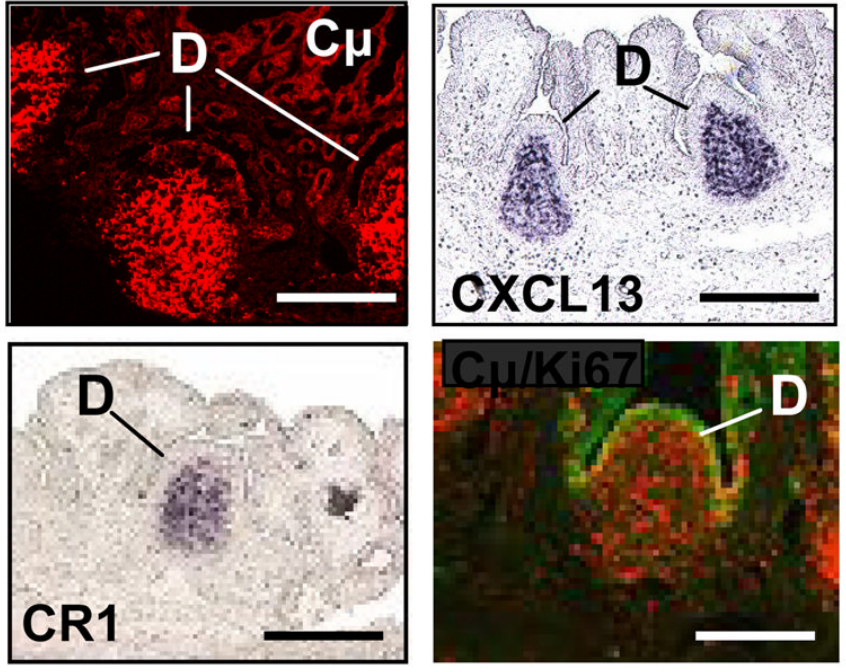

B B. fragilis + B. subtilis
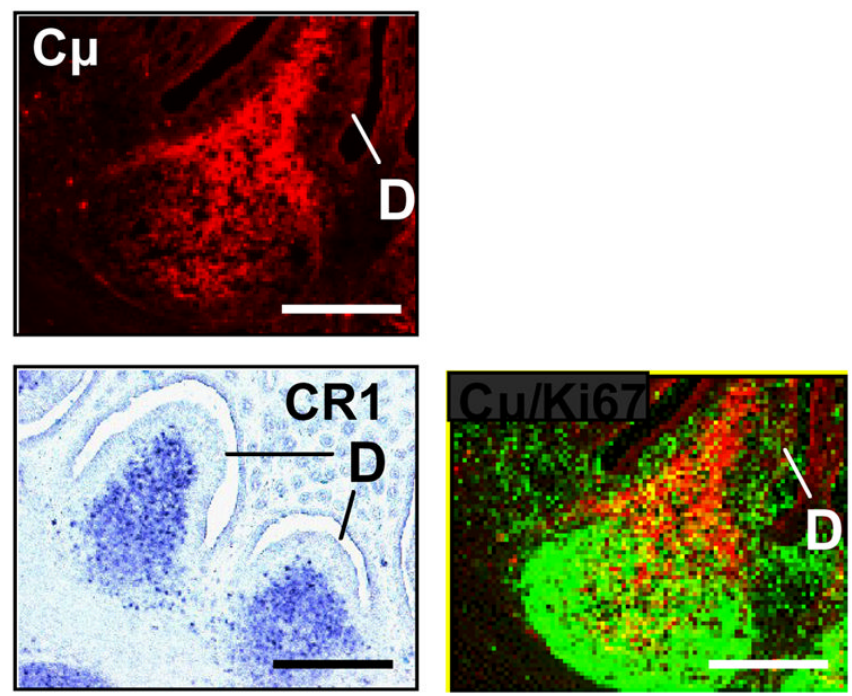

Figure 5.

Immunohistochemical and in situ hybridization analysis of appendix sections from 7-weekold LigApx rabbits. A, germ-free appendix sections stained with: anti- $\mu$ mAb (top left); CXCL13 riboprobe (top right); CR1 riboprobe (bottom left); anti- $\mu$ (red) and Ki67 (green) $\mathrm{mAbs}$ (bottom right). $B$, Sections from ligated appendix into which $B$. fragilis $+B$. subtilis were introduced, stained with: anti- $\mu \mathrm{mAb}$ (top panel); CR1 riboprobe (bottom left); anti- $\mu$ (red) and Ki67 (green) mAbs (bottom right). Appendix sections are from rabbits in which the appendix was ligated at birth and either kept germ-free $(A)$ or inoculated with $B$. fragilis and $B$. subtilis at 3 weeks of age $(B)$, as described in [10]. All rabbits were sacrificed for tissue analysis at 7 weeks of age. D, dome. Magnification: 100X; Scale bars: $250 \mu \mathrm{m}$. 

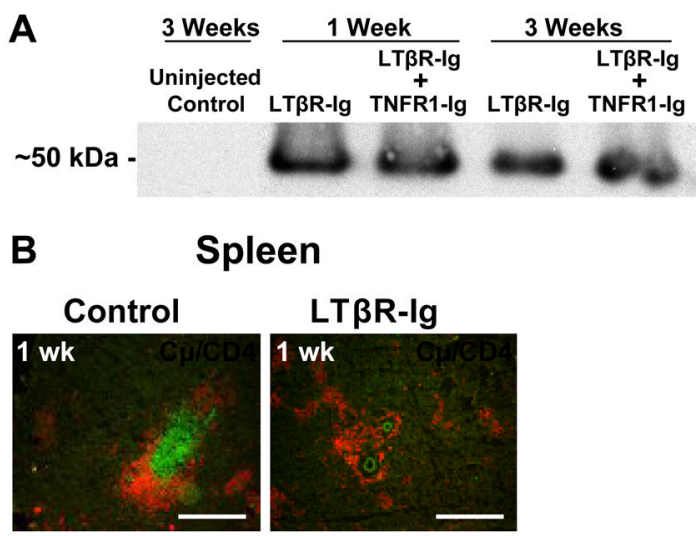

\section{Spleen}
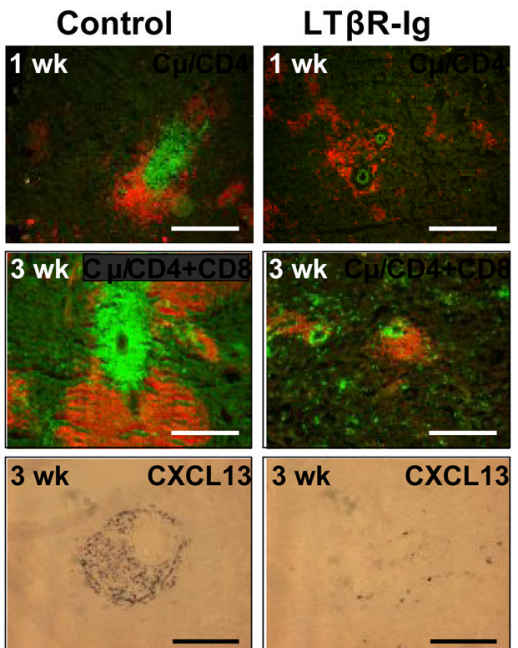

C Appendix
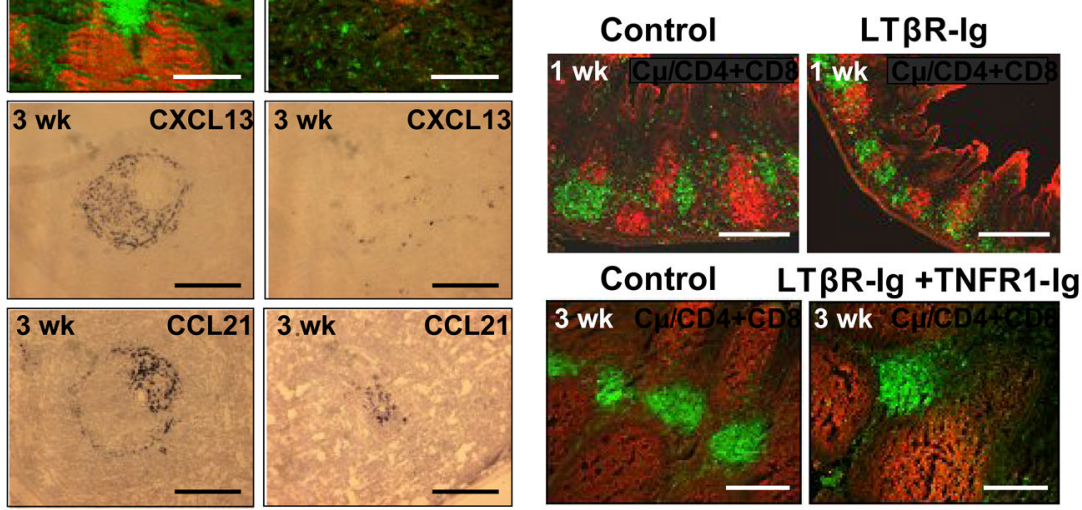

Figure 6.

Western blot analysis of sera $(A)$ and immunohistochemical and RNA in situ hybridization analysis of spleen $(B)$ and appendix $(C)$ tissue sections from rabbits treated with soluble LT $\beta$ R-Ig and TNFR1-Ig fusion proteins. A, Western blot analysis of recombinant viral fusion proteins in sera of treated rabbits (serum concentrations were determined as described in Materials and Methods, and are listed in parentheses). Lane 1,3-week-old uninjected littermate control rabbit; lanes 2 and 3, 1-week-old rabbits treated with LT $\beta \mathrm{R}-\mathrm{Ig}(221 \mu \mathrm{g} / \mathrm{ml})$ andLT $\beta \mathrm{R}$ Ig + TNFR1-Ig ( $243 \mu \mathrm{g} / \mathrm{ml})$ recombinant viruses, respectively; lanes 4 and 5, 3-week-old rabbits treated with LT $\beta R-\operatorname{Ig}(204 \mu \mathrm{g} / \mathrm{ml})$ andLT $\beta R-I g$ + TNFR1-Ig $(259 \mu \mathrm{g} / \mathrm{ml})$ recombinant viruses, respectively; expected sizes of the LT $\beta$ R-Ig and TNFR1-Ig fusion proteins are both $50 \mathrm{kDa}$. $B$, Spleen sections from: 1 -week-old rabbits stained with anti- $\mu$ (red) and anti-CD4 (green) mAbs (top row); 3-week-old rabbits stained with anti- $\mu$ (red) and anti-CD4 + anti-CD8 (green) mAbs (second row), CXCL13 (third row) and CCL21 (bottom row) riboprobes. C, Appendix sections from: 1-week-old rabbits stained with anti- $\mu$ and anti-CD4 + anti-CD8 (green) mAbs (top row); 3-week-old rabbits stained with anti- $\mu$ (red) and anti-CD4+ anti-CD8 (green) (bottom row). Results representative of 3 experiments with 1 rabbit receiving each treatment per experiment. Magnification: 100X; Scale bars: $250 \mu \mathrm{m}$. 

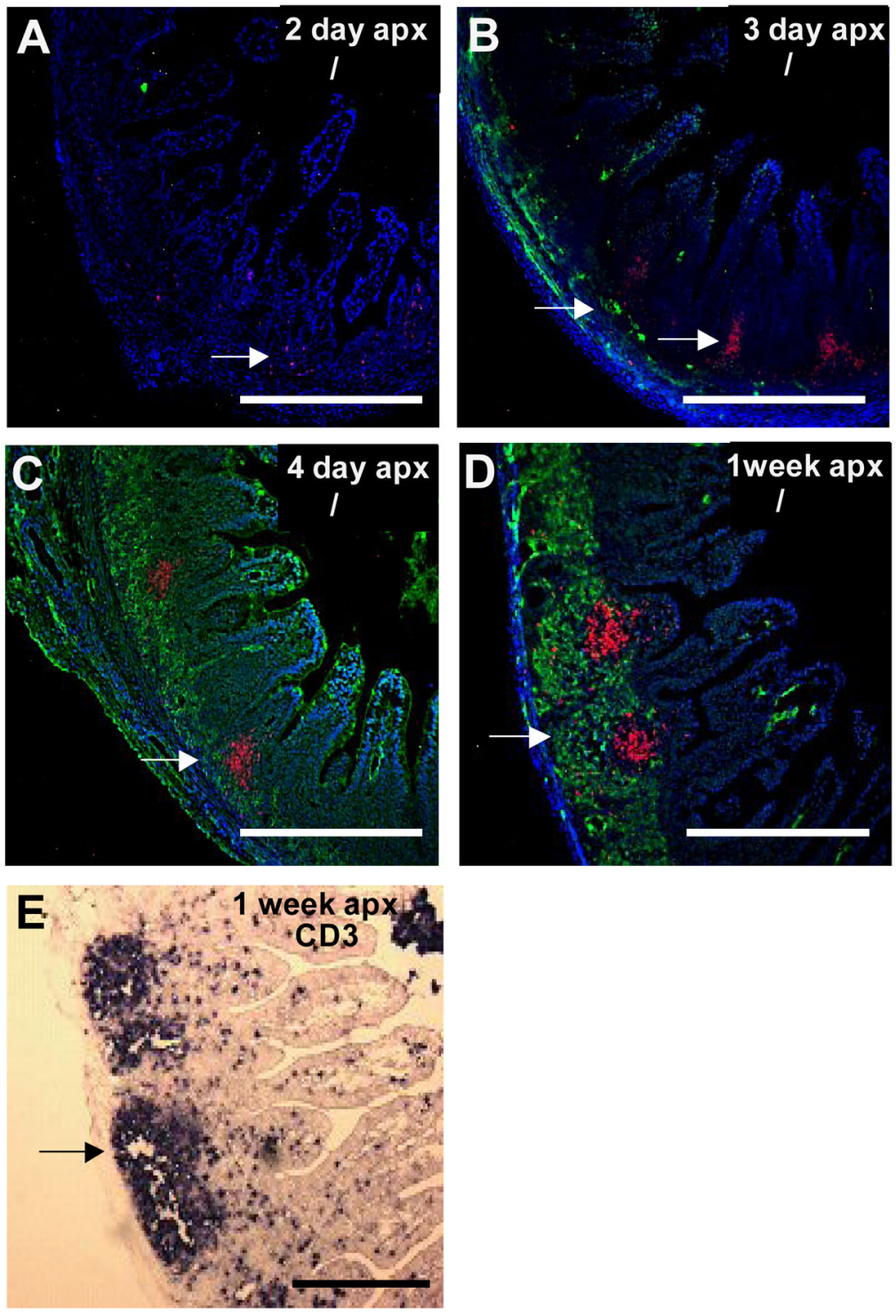

Figure 7.

In situ hybridization analysis of neonatal rabbit appendix. Two-color in situ hybridization with $\mathrm{C} \mu$ (red) and CCL21 (green) riboprobes of appendix sections from: $A$, 2-day-old, $B$, 3-day-old, $C$, 4-day-old and $D, 1$-week-old rabbits. $E$, appendix section from 1-week-old rabbit stained with CD3 riboprobe. Arrows: B cells ( $A$ and $B)$, CCL21 mRNA expression $(B, C$ and $D), \mathrm{T}$ cells $(E)$. Magnification: 100X; Scale bars: $250 \mu \mathrm{m}$. 


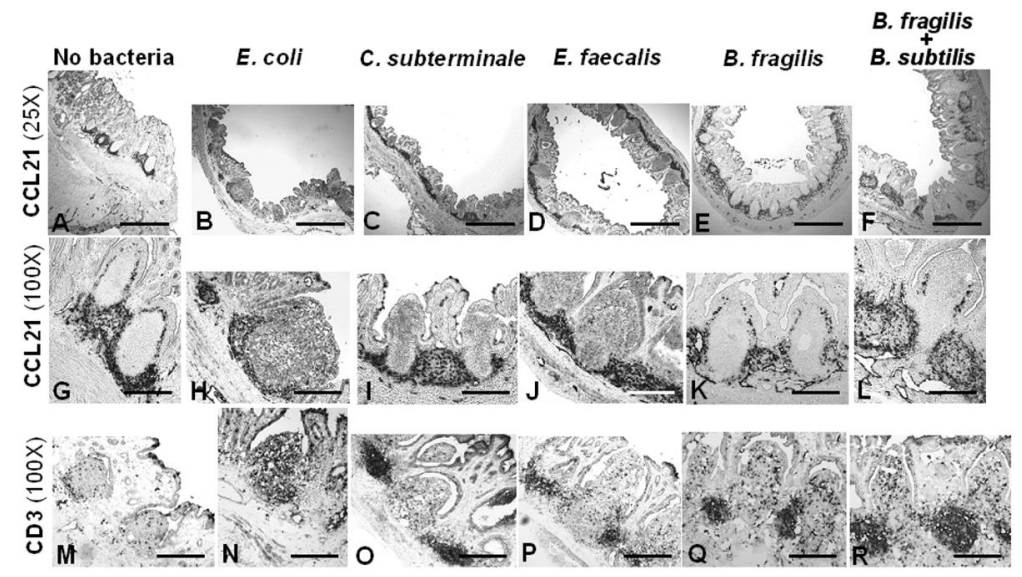

Figure 8.

CCL21 and CD3 in situ hybridization analysis of appendix sections from 7-week-old LigApx rabbits. Sections from germ-free (first column) and ligated appendix inoculated with $E$. coli (second column), Clostridium subterminale (third column), Enterobacter faecalis (fourth column), Bacteroides fragilis (fifth column) or Bacteroides fragilis + Bacillus subtilis (sixth column) stained with: CCL21 riboprobe (top row (25X), middle row (100X)); CD3 riboprobe (bottom row $(100 \mathrm{X})$ ). Appendix sections are from rabbits in which the appendix was ligated at birth and either kept germ-free (first column) or inoculated with intestinal commensal isolates at 3 weeks of age (all other columns), as described in [10]. All rabbits were sacrificed for tissue analysis at 7 weeks of age; Scale bars: $1 \mathrm{~mm}(25 \mathrm{X}), 250 \mu \mathrm{m}(100 \mathrm{X})$. 


\section{Table 1}

PCR primers used to generate in vitro transcription templates for riboprobe synthesis. ${ }^{1,2}$

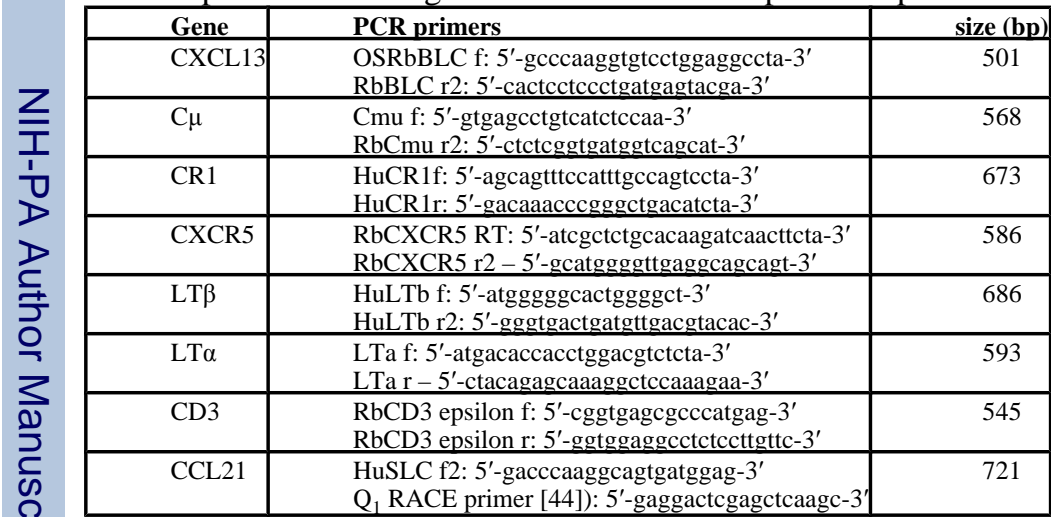

흔. $\quad l_{\mathrm{Rb}}$, rabbit-specific primer; Hu, human-specific primer; f, forward primer; r, reverse primer.

2 The CCL21 in vitro transcription template cDNA was cloned using 3' RACE according to Frohman [44]. 